\title{
Kinesiophobia, Self-efficacy and Pain-related Disability in Patients with Non-specific Low Back Pain
}

\author{
Odole A.C., ${ }^{1}$ Ogunlana M.O., ${ }^{2}$ Dada O. , ${ }^{3}$ Williams O.O. ${ }^{2}$ \\ ${ }^{1}$ Department of Physiotherapy, Faculty of Clinical Sciences, University of Ibadan, Oyo State, Nigeria \\ ${ }^{2}$ Department of Physiotherapy, Federal Medical Centre, Abeokuta, Ogun State, Nigeria \\ ${ }^{3}$ Department of Physiotherapy, University of Ibadan Health Centre, Oyo State, Nigeria \\ Correspondence \\ Dr. Michael Opeoluwa Ogunlana, Department of Physiotherapy, Federal Medical Centre, Abeokuta, Ogun \\ State, Nigeria・opeoluwamic@yahoo.com
}

\section{SUMMARY}

Psychological factors like kinesiophobia and self-efficacy have been shown to be associated with pain and disability perception in patients with non-specific low back pain (NSLBP). The association among extent of kinesiophobia, self efficacy, pain intensity and disability in patients presenting with NSLBP and the predictor of disability among pain intensity, self-efficacy and kinesiophobia in these patients were investigated in this study.

The research design was an analytical cross sectional survey involving 275 consecutively selected individuals diagnosed with NSLBP at a tertiary hospital in southwestern Nigeria. The main outcome measures used were: Quadruple Visual Analogue Scale (QVAS), Tampa Scale for Kinesiophobia (TSK), Revised Oswestry Disability Questionnaire (RODQ) and Self-Efficacy in Rehabilitation Scale (SER).

The mean age of the participants was $51.62 \pm 13.4$ years. The extent of kinesiophobia and measure of selfefficacy were high and above average as seen in $71.7 \%$ and $94.3 \%$ of the participants respectively. The mean scores on TSK, RODQ, SER and pain intensity were 39.45 $\pm 5.91,36.98 \pm 15.97,98.68 \pm 21.4$ and $7.35 \pm 1.94$ respectively. Participants with high scores on TSK had significantly high scores on RODQ and low scores on SER. There was a significant positive association between extent of kinesiophobia, disability and selfefficacy $(p<0.05)$. Self-efficacy, pain intensity and kinesiophobia significantly predicted extent of disability $(\mathrm{p}<0.05)$.

Patients with NSLBP exhibited fear of re-injury (kinesiophobia). Patients with high level of kinesiophobia had increased pain intensity and reduced self-efficacy. High levels of kinesiophobia accompanied by increased pain intensity and decreased self-efficacy were significant predictors of pain related disability in patients with NSLBP.

KEY WORDS: Non-specific low back pain, self-efficacy, kinesiophobia, perceived disability

\section{INTRODUCTION}

Management of low back pain (LBP) is a challenge for health care professionals and constitutes a burden to the health care system as a whole (Brunner et al, 2012). Approximately $20-56 \%$ of adults experience LBP at some time during a period of 1 year (Hoy et al, 2010). Patients with LBP suffer from physical discomfort, and functional limitations that may cause disability and interfere with their quality of life (Horng et al, 2005). Chou and Huffman (2007) recommended that LBP can be classified into 3 broad categories: non-specific low back pain, low back pain potentially associated with radiculopathy or spinal stenosis, or low back pain potentially associated with another specific spinal cause. Low back pain can interfere with activities 
ranging from basic activities of daily living, such as walking and dressing, to many work-related functions. It might seem obvious that pain determines disability in patients with LBP but studies (Brunner et al, 2012; Pincus et al, 2002) have shown that the intensity of pain and the extent of disability do not correlate well and both are associated with different risk factors (Kovacs et al, 2005). Psychological factors like kinesiophobia and self-efficacy have been shown to be associated with pain and disability perception in patients with NSLBP.

Kinesiophobia is one of the most extreme forms of fearrelated movement (Simon, 2010). It is an irrational fear of re-injury due to movement that cannot be substantiated. Fear of movement or fear of re-injury or pain may lead to and sometimes increases the extent of disability in patients and is a significant determinant of prolonged work-related disability (Vlaeyen et al, 1995).This is evident in the fear avoidance model (Vlaeyen et al, 1995). The model predicts that catastrophic thinking following the onset of pain will contribute to heightened fears of movement and increased hypervigilance to pain symptoms. In turn, fear is expected to lead to avoidance of or escape from any activity that might be associated with pain (Vlaeyen and Linton, 2000). Prolonged inactivity is expected to contribute to depression and disability (Sullivan et al, 2006). Hypervigilance is expected to contribute to further increases in pain severity. The model is recursive such that increased pain symptoms, distress and disability become the input for further fear of re-injury due to movement.

Self-efficacy describes a person's belief in his or her personal capabilities (Bandura, 1997). Efficacy expectations with regard to pain control, management, coping and daily functioning may help to determine the extent of disability (Arnstein et al, 1999). Self-efficacy helps to determine how well a patient adapts to pain (Anderson et al, 1995) and may explain the variability between a patient's perceived level of activity and his actual performance (Gage and Polatojko, 1994; Strong, 1995). If pain cannot totally explain disability, the inclusion of self-efficacy might further aid the explanation of pain behaviour (Gage and Polatojko, 1994). An accurate assessment of a patient's disability and selfefficacy is useful in reducing pain and increasing physical functioning in chronic pain (Harrison, 2004). Various studies (Levin et al,1996; Costa et al, 2011; Wittink et al, 2003; Meredith et al, 2006) conducted in developed countries among patients with chronic pain have shown that pain intensity, self-efficacy and physical performance are related, though the pattern of relationship reported in these studies varies. Adegoke and Ezeukwu (2010) concluded that increase in self-efficacy was significantly related to improvement in the physical performance of patients with chronic low back pain. Hence, with improving selfefficacy, there is a decrease in pain-related disability.

It appears that the few published studies on the associations among the extent of kinesiophobia, selfefficacy, pain intensity and disability are available for referencing (Adegoke and Ezeukwu 2010; Arnstein et al 1999, Strong, 1995). The authors of these studies only investigated the association between the extent of kinesiophobia, level of self-efficacy and disability in patients with chronic pain. The determinant of disability among kinesiophobia, pain intensity and self-efficacy in patients with acute and chronic pain as well as the associations among the extent of kinesiophobia and level of self-efficacy, pain intensity and disability in patients presenting with low back pain were investigated in this study.

\section{METHODS}

\section{Study population and design}

This study was an analytical cross-sectional survey. Participants were patients receiving treatment at the physiotherapy out-patient clinics of the Federal Medical Centre, Abeokuta, Ogun State and the State Hospital, IjayeAbeokuta, Ogun State, Nigeria. Each clinic had an average attendance of 20 patients per week. The inclusion criterion was that participants (who were individuals diagnosed with LBP of non-specific aetiology) involved in this study should comprehend instructions in English and/or Yoruba languages since Yoruba is the major language of communication in South-western Nigeria where the study was carried out. Patients with co-morbidity that may influence overall well-being, such as cancer, vertebral or spinal infections, referred pain from internal organs, or psychological pathology, were excluded from this study.

Sample size was determined using data from a previous study (Louw et al, 2007), in which the proportion of the population of LBP patients was 0.62 and assuming an alpha of 0.05 and beta of 0.10 and a 2 -tailed test with a difference of 0.06 . It was adequate to involve at least 252 participants in the study. Participants were recruited as they became available at the clinics. Ethical approval for the study was obtained from the University of Ibadan/University College Hospital Ethics Committee (UI/UCH/12/0360), Federal 
Medical Centre Health Research Committee (FMCA/12/HREC/238/2013) and participants' informed consent was obtained.

\section{Measurements and Instruments}

Participants' socio-demographic variables (gender, age, marital status, religious affiliation and educational status) and clinical variables (weight, height and duration of NSLBP) were obtained.

The Tampa Scale of Kinesiophobia (TSK) by SwinkelsMeewisse et al (2003), developed to measure fear of movement in persons with musculoskeletal pain, was used in this study. The TSK consists of 17 statements capturing the idea that pain is a signal for re-injury because of physical activity or certain movements. Respondents were asked to indicate their level of agreement on a 4-point rating scale. A high score indicates a high level of kinesiophobia (Swinkels-Meewisse et al, 2003). The total score ranges between 17 and 68. A high score on the TSK indicates a high extent of kinesiophobia and a score of 37 serves as a cutoff that differentiates between high and low extent of kinesiophobia (Swinkels-Meewisse et al, 2003). Internal consistency of TSK scores range from alpha $=0.70$ to 0.83 . Test-retest reliability ranges from $\mathrm{r}(\mathrm{s})=0.64$ to 0.80 $(\mathrm{P}<0.01)$. Concurrent validity is moderate, ranging from $\mathrm{r}(\mathrm{s})=0.33$ to $0.59(\mathrm{P}<0.01)$ (Swinkels-Meewisse et al, 2003).

Self-efficacy in Rehabilitation for LBP (SER) by Woby et al (2007) was used to assess functional self-efficacy. This provides 12 questions regarding one's ability to perform activities related to the treatment of the back. A low score relates to low perceived self-efficacy, while a high score predicts high perceived self-efficacy. SER has excellent internal consistency $(\mathrm{a}=0.88)$ and good test-retest reliability $(r=0.88)$ (Woby et al; 2007).

The Quadruple visual analog scale by Von Korff et al (1993) was used to assess pain intensity. This scale measures pain intensity at four levels: "pain right now", "average pain", "best pain" and "worst pain". It consists of four visual analog scales. Each scale consists of a line that is $10 \mathrm{~cm}$ long, the ends of which are marked with the extreme states of the items being measured (Von Korff et al, 1993). The subscale of 'worst pain' intensity was used for analysis in this research.

The Revised Oswestry Disability Questionnaire (RODQ) by Davidson and Keating (2002) was used to measure disability associated with NSLBP. It is based on ten sections with six levels each, assessing the limitation of various activities of daily living (Fairbank and Pynsent, 2000; Davidson and Keating, 2002). The range of possible values is from 0 (the best health state) to 100 (the worst health state). Scoring of this questionnaire was done to compute the Disability Index Percent (DIP). For each section of the questionnaire, the total possible score is 5 . The first statement was scored 0 and consecutive statements were scored 1 to 5 . The total score was then divided by the total possible score and expressed in percentage to produce the disability index percent. The DIP is interpreted as:

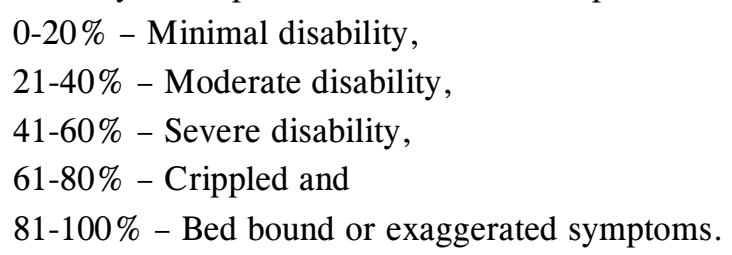

The RODQ was administered to each participant by interview. The RODQ is a valid, reliable, and responsive condition-specific assessment tool that is suited for use in clinical practice. It is easy to administer and score, objectifies clients' complaints, and monitors the effects of therapy.

\section{Statistical Analysis}

Descriptive statistics of frequency distribution, mean, standard deviation and percentages were used in summarizing the socio-demographic and clinical characteristics of the participants. The proportions of patients presenting with NSLBP who had high scores in kinesiophobia were also investigated using frequency distribution tables. The association among pain intensity, disability, self-efficacy and kinesiophobia was investigated using Spearman's rank correlation. The predictor of disability among self-efficacy, pain intensity and kinesiophobia was investigated using multiple linear regressions.

\section{RESULTS}

Two hundred and eighty five (285) patients with NSLBP were invited to participate in this study, out of which 275 participated; thus giving a response rate of $96.4 \%$. The mean age of the participants was $51.62 \pm 13.4$ years. Less than half of the respondents $(40 \%)$ were male and more than half had tertiary education $(56.4 \%)$. The majority (85.5\%) were from the Yoruba ethnic group and $73.3 \%$ were married. More than half of the participants were Christians $(63.6 \%)$. With regard to their social group, 
$75.6 \%$ of the participants belong to the white-collar social class. The frequency distribution of social and demographic characteristics of respondents is presented in table 1. Out of the 275 participants, $85.5 \%$ of the respondents had LBP for more than 6 weeks and $45.5 \%$ of these participants had moderate disability.

Table 1. Sociodemographic characteristics of participants

\begin{tabular}{llcc}
\hline Variable & Characteristics & $\begin{array}{c}\text { Frequency } \\
(\mathrm{n}=275)\end{array}$ & $\begin{array}{c}\text { Percentage } \\
(\%)\end{array}$ \\
\hline Gender & Male & 110 & 40 \\
Educational & Female & 165 & 60 \\
status & None & 10 & 3.6 \\
& Primary & 55 & 20 \\
& Secondary & 25 & 9.1 \\
& Tertiary & 155 & 56.4 \\
Tribe & Others & 30 & 10.9 \\
& Yoruba & 235 & 85.5 \\
& Hausa & 25 & 9.1 \\
& Igbo & 5 & 1.8 \\
Marital status & Others & 10 & 3.6 \\
& Single & 65 & 23.6 \\
& Married & 201 & 73.1 \\
Religion & Widowed & 9 & 3.3 \\
& Christianity & 175 & 63.6 \\
Social class & Islam & 100 & 36.4 \\
& White collar & 215 & 78.2 \\
& Blue collar & 15 & 5.5 \\
& Self employed & 45 & 16.4 \\
\hline
\end{tabular}

It was observed that the extent of kinesiophobia and level of self-efficacy were high and above average as seen in $71.7 \%$ and $94.3 \%$ of the participants respectively (table 2). The mean score on the TSK was $39.45 \pm 5.91$ while the mean score on RODQ was $36.98 \pm 15.97$ and the mean score on the SER scale was $98.68 \pm 21.4$. On the average, the participants rated their worst level of pain as $7.35 \pm 1.94$.

Table 2. Clinical characteristics of participants

\begin{tabular}{llcc}
\hline Variable & Characteristics & $\begin{array}{c}\text { Frequency } \\
(275)\end{array}$ & $\begin{array}{c}\text { Percentage } \\
(\%)\end{array}$ \\
\hline Duration of pain & Less than 6 weeks & 10 & 3.6 \\
& Btw 6 - 12 weeks & 30 & 10.6 \\
& More than 12 weeks & 235 & 85.5 \\
Extent of & Low Kine. & 78 & 28.3 \\
Kinesiophobia & High Kine. & 197 & 71.7 \\
Level of Self- & Below Average & 16 & 5.7 \\
efficacy & Above Average & 259 & 94.3 \\
Degrees of & Mild disability & 45 & 16.4 \\
disability using & Moderate disability & 125 & 45.5 \\
RODQ Scores & Severe disability & 80 & 29.1 \\
& Crippled & 10 & 3.6 \\
& Bedridden or & & \\
& catastrophizing & 5 & 1.8 \\
\hline
\end{tabular}

Participants with high extent of kinesiophobia had higher pain intensity scores but this was not statistically significant $(p=0.184)$. Participants who reported high scores on the TSK had significantly high scores on the RODQ and low scores on the SER scale. Hence, a high extent of kinesiophobia was significantly associated with increasing level of disability and decrease in self-efficacy $(\mathrm{p}<0.001)$. Table 3 shows the association among the extent of kinesiophobia, levels of self-efficacy, pain and functional disability. Multiple linear regression revealed that selfefficacy, pain intensity and kinesiophobia significantly predicted extent of disability $(\mathrm{p}<0.05)$. Kinesiophobia and pain intensity contributed 24 and 22 units' variances to extent of disability respectively (table 4 ).

Table 3. Association between the extent of kinesiophobia and level of self-efficacy, pain and disability

\begin{tabular}{llll}
\hline Variable & Characteristics & Mean \pm SD & p-value \\
\hline Pain & Low Kine. & $7.13 \pm 1.56$ & 0.184 \\
& High Kine. & $7.45 \pm 2.10$ & \\
Disability & Low Kine. & $29.47 \pm 15.79$ & $<0.001$ \\
& High Kine. & $40.43 \pm 14.99$ & \\
Self-efficacy & Low Kine. & $108.93 \pm 10.36$ & $<0.001$ \\
& High Kine. & $95.81 \pm 23.12$ & \\
\hline
\end{tabular}

Table 4. Predictors of pain-related disability

\begin{tabular}{lccccc}
\hline & $\begin{array}{l}\text { Unstandard } \\
\text { ized Beta } \\
\text { Coefficient }\end{array}$ & $\begin{array}{l}\text { Standardized } \\
\text { Beta } \\
\text { Coefficient }\end{array}$ & p-value & $\begin{array}{c}\text { Lower } \\
\text { CI }\end{array}$ & $\begin{array}{c}\text { Upper } \\
\text { CI }\end{array}$ \\
\hline $\begin{array}{l}\text { Constant } \\
\text { Self- } \\
\text { efficacy }\end{array}$ & 11.59 & - & 0.263 & -8.74 & 31.925 \\
$\begin{array}{l}\text { Score } \\
\text { TSK }\end{array}$ & -0.13 & -0.17 & 0.009 & -0.227 & -0.032 \\
$\begin{array}{l}\text { Score } \\
\text { Pain }\end{array}$ & 0.64 & 0.24 & 0 & 0.313 & 0.964 \\
$\begin{array}{l}\text { Intensity } \\
\text { Score }\end{array}$ & 1.76 & 0.22 & 0 & 0.787 & 2.723 \\
\hline
\end{tabular}

\section{DISCUSSION}

In order to provide effective rehabilitation for NSLBP it is necessary to explore both physiological and psychological factors as predictors of disability and rehabilitation outcomes (Simons, 2010). Psychological factors like kinesiophobia and self-efficacy have been shown to be associated with pain and disability perception in patients with NSLBP. This study documents the proportion of patients with LBP who exhibited kinesiophobia and the inter-relationship of pain intensity, kinesiophobia, self- 
efficacy and functional disability. The high proportion of patients who exhibited kinesiophobia in this study may be reflective of the high proportion of these patients who have had pain for a long duration, i.e., more than 12 weeks (chronic pain). It could be assumed that such patients waited for pain relief for more than 12 weeks. It seems that patients who wait for such a long period tend to adopt coping strategies. Pain responses such as resting and guarding the lower back have been described as passive coping and viewed as reflecting patient-perceived helplessness in controlling pain or reliance on others for pain management. Resting and guarding consistently have been found to be associated with worse outcomes and thus have been considered maladaptive for chronic pain (Carroll et al, 2002; Tan et al, 2005).

The findings from the present study reveal that high extent of kinesiophobia contributed greatly to the increasing level of disability. Previous researchers have also reported that patients with higher pain intensity have significant positive correlations with disability and significant negative correlation with self-efficacy (Arnstein, 2000). This suggests that a high level of pain-related fear and pain intensity might lead to a high level of disability. The high correlation of pain intensity and kinesiophobia on the extent of disability suggests that the more intense the pain and the greater the fear of movement, the more the functional disability experienced by the patient. This might interfere with the patient functional abilities which could undermine home or family responsibilities, recreation, social activities, occupation, sexual behaviour, self-care and life-support activities.

The outcome of this study conflicted with the results obtained by Woby et al (2007) which concluded that selfefficacy was the most important predictor of disability. They reported that cognitive factors such as pain-related fear (kinesiophobia) were found to lack the same predictability as self-efficacy. This study shows that selfefficacy had a significant predictability to the extent of disability of patients with low back pain, albeit an inverse relationship. Therefore, evaluating and bolstering the patient's belief in their own abilities may be an important component of therapy (Arnstein, 2000). As in earlier studies, the result of this investigation suggests that both increased pain intensity and decreased self-efficacy contributed to the development of disability in patients with pain. These results imply that a lack of belief in one's own ability (to manage pain, function and cope) may predict the extent to which individuals with pain become limited in their activity. Nevertheless, self-efficacy beliefs, levels of functioning and other identified variables did not eliminate the strong influence that high pain intensity has on disability (Arnstein et al, 1999). Further research is still needed to elucidate causal pathways between self-efficacy and adjustment to acute or chronic pain.

\section{Conclusion}

The majority of patients with NSLBP exhibited fear of reinjury (kinesiophobia). Patients with high extent of kinesiophobia had increased pain intensity and reduced selfefficacy. High extent of kinesiophobia accompanied by increased pain intensity and decreased self-efficacy were significant determinants of pain-related disability in patients with NSLBP.

\section{Authors' contributions}

A.C.O. and M.O.O. participated in the acquisition of data, conceptualization of the study, and performed statistical analyses; O.D and O.O.W reviewed the data analysis results. All authors contributed to drafting and critically revising the manuscript.

\section{Conflicts of interest}

The authors declare that they have no competing interests.

\section{Funding/support}

This project was fully funded by the Samuel-Adesola Ogunlana Foundation of Sholuyi Estate Gbagada Lagos Nigeria.

Acknowledgements: The authors acknowledge all the participants.

\section{References}

Adegoke B.O.A., Ezeukwu A.O. 2010. Pain intensity, self-efficacy and physical performance in patient with chronic low back pain. International Journal of Therapy and Rehabilitation 17(10).

Anderson K.O., Dowds B.N., Robyn P.E., Edwards W.T., Peeters-Asdoyuriam, C. 1995. Development and initial validation of a scale to measure self-efficacy beliefs in patients with chronic pain. Pain 63(1): 77-84.

Arnstein P., Caudill M., Mandle C.L., Norris A., Beasley, R.1999. Self-efficacy as a mediator of the relationship between pain intensity, disability and depression in chronic pain patients. Pain 80: 483-491. 
Arnstein P. 2000. The mediation of disability by self-efficacy in different samples of chronic pain patients. Disability and Rehabilitation 22(17): 794-801.

Bandura, A. 1997. Insights. Self-efficacy. Harvard Mental Health Letter 13(9): 4-6. Retrieved from CINAHL.

Brunner E., De Herdt A., Minguet P., Baldew S., Probst M. 2012. Can cognitive behavioural therapy based strategies be integrated into physiotherapy for the prevention of chronic low back pain? A systematic review. Disability \& Rehabilitation DOI: $10.3109 / 09638288$.

Carroll L., Mercado A.C., Cassidy J.D., Cote P. 2002. A population-based study of factors associated with combinations of active and passive coping with neck and low back pain. $J$ Rehabil Med 34: 67-72.

Chou R., Huffman L.H. 2007. Guideline for the evaluation and management of low back pain: Evidence Review. American Pain Society Glenview. Chronic low back pain: a randomised controlled trial. European Spine Journal 17: 1193-2000.

Costa L., Da C.M., Maher C.G., Mcauley J.H., Hancock M.J. Smeets R.J. 2011. Self-efficacy is more important than fear of movement in mediating the relationship between pain and disability in chronic low back pain. European Journal of Pain 15: 213-219.

Davidson M., Keating, J.A. 2002. Comparison of five low back disability questionnaires reliability and responsiveness. Physical Therapy 82: 8-24.

Fairbank J.C.T., Pynsent P.B. 2000. The Oswestry Disability Index. Spine 25(22): 2940-2953.

Gage M., Polatojko H.J. 1994. Enhancing occupational performance through an understanding of perceived selfefficacy. American Journal of Occupational Therapy 48(5): 452-61.

Harrison A.L. 2004. The influence of pathology, pain and coping on function in women with knee osteoarthritis. Physical Therapy 84: 822-831.

Horng Y.S., Hwang Y.H., Wu H.C., Liang H.W., Jang Y., Twu F.C., Wang, J.D. 2005. Predicting health related quality of life in patients with low back pain. Spine 30(55): 1-5.

Hoy D., Brooks P., Blyth F., Buchbinder R. 2010. The epidemiology of low back pain. Best Pract Res Clin. Rheumatol 24(6): 769-81. doi: 10.1016/j.berh.2010.10.002

Kovacs F.M., Abiara V., Zamora J., Fernandez C. 2005. The Spanish Back Pain Research Network. The transition from acute to sub-acute chronic low back pain. A study based on determinants of quality of life and prediction of chronic disability. Spine 30: 1786-1792.

Levin J.B., Lofand K.R., Cassisi J.E., Poreh A.M., Blonsky E.R. 1996. The relationship between self-efficacy and disability in chronic low back pain patients. International Journal of Rehabilitation Health 2(1): 19-28.

Louw Q.A., Morris L.D., Grimmer-Somers K. 2007. The prevalence of low back pain in Africa: A systemic review. BMC Muscukoskeletal Disorders 8: 105.

Meredith P.J., Strong J., Feeney J.A. 2006. The relationship of adult attachment to emotion, catastrophising, control, threshold and tolerance, in experimentally-induced pain. Pain 120: 44-52. PubMed PMID: 16359795.

Pincus T., Burton A.K., Vogel S., Field A.P. 2002. A systematic review of psychological factors as predictors of chronicity/disability in prospective cohorts of low back pain. Spine 27(5): E109-120.

Simon J. 2010. Self-efficacy, kinesiophobia and pain anxiety as predictors of outcomes from rehabilitation of low back pain. http://www.msubillings.edu/hhp/Senior\%2520Thesis\%2520E xamples/RehabilitationS10.pdf

Strong J. 1995. Self-efficacy and the Patients with Chronic Pain; Moving in on Pain. Melbourne: Butterworth- Heinemann.

Sullivan M.J.L., Adams H., Rhodenizer T., Stanish W.D. 2006. A psychosocial risk factor-targeted intervention for the prevention of chronic pain and disability following whiplash injury. Physical Therapy 86: 8-18.

Swinkels-Meewisse E., Swinkels R., Verbeek A., Vlaeyen J. Oostendorp R. 2003. Psychometric properties of the Tampa scale for kinesiophobia and the fear-avoidance beliefs for questionnaire in acute low back pain. Manual Therapy 8(1):2936.

Tan G., Nguyen Q., Anderson K.O., Jensen M.P., Thornby J. 2005. Further validation of the Chronic Pain Coping Inventory. J Pain 6: 29-40.

Vlaeyen J.W., Linton S.J. 2000. Fear-avoidance and its consequences in chronic musculoskeletal pain: A state of the art. Pain 85(3): 317-332.

Vlaeyen J.W., Kole-Snijders A.M., Boeren R.G., van Eek H. 1995. Fear of movement/ (re)injury in chronic low back pain and its relation to behavioural performance. Pain 1995; 62(3): 363-372.

Von Korff M., Deyo R.A., Cherkin D., Barlow W. 1993. Back pain in primary care: Outcomes at 1 year. Spine 18: 855-62.

Wittink H., Rogers W., Sukiennik A., Carr D.B. 2003. Physical functioning: Self-report and performance measures are related but distinct. Spine 28: 2407-13.

Woby S.R., Roach N.K., Urmston M., Watson P.J. 2007. The relation between cognitive factors and levels of pain and disability in chronic low back pain patients presenting for physiotherapy. European Journal of Pain 11: 869-877. doi:10.1016/j.ejpain.2007.01.005 